\title{
$H-2$ and Background Influences on Tissue Grafts Across the H-Y Barrier
}

\author{
Roberta DeMott-Friberg, Theodore F. Beals, and Jane S. Schultz \\ Veterans Administration Medical Center, Ann Arbor, Michigan 48105, and Departments of Genetics \\ and Pathology, University of Michigan, Ann Arbor, Michigan 48109
}

\begin{abstract}
Male liver was grafted to kidney beds in syngeneic female mice. Relative influences of $H$-2 haplotype, genetic background or interaction of $\mathrm{H}-2$ haplotype with genetic background on anti-H-Y response were evaluated using 27 inbred strains carrying eight $\mathrm{H}-2$ haplotypes of independent origin and three naturally occurring recombinants. Females of $H-2^{b}$ haplotype acutely rejected the male graft as is reported for other tissue graft systems. An $H-2$ haplotype influence was found for all haplotypes studied, with a greater variation of immunologic response revealed by histological analysis of liver grafts than is demonstrated by skin grafts. Strains carrying $H-2^{k}, H-2^{j}$ and $H-2^{p}$ haplotypes expressed the greatest range of immunological variability with responses ranging from graft proliferation to graft rejection. Strains carrying the $H-2^{d}$ haplotype had the most consistent responses with little reaction to the graft. The strong immune response by SJL/J $\left(H-2^{s}\right)$ female mice to the $\mathrm{H}-\mathrm{Y}$ antigen is not typical of other $H-2^{s}$ strains, but is compatible with the reported hyperresponsiveness of this strain to alloantigens.
\end{abstract}

\section{Introduction}

The ability of certain female mice to reject grafts from syngeneic males has created much interest since Eichwald's and Silmser's original observations (1955). An extensive review by Gasser and Silvers (1972) summarizes the many lines of investigation that have been pursued in attempts to explain the difference in male and female immunologic responses (if a female mouse was created from the rib of a male mouse, can male tissue be nonself?). It is now recognized that the female response to the male antigen is part of the histocompatibility phenomenon, and that the degree of response is, in fact, largely influenced by the female's $H$-2 type (Bailey and Hoste 1971 and Gasser and Silvers 1971a). Klein and Linder (1961) have presented skin graft data with a 2-gene model explaining this response. Bailey (1971) 
and Stimpfling and Reichert (1971), using a variety of both recombinant and nonrecombinant mouse strains, have mapped the responsible gene(s) within or near the $H-2$ complex. A comprehensive skin graft study among nonrecombinant strains (Bailey 1971) has revealed that, rather than a single, discrete gene action limited to the $H-2^{b}$ haplotype, there is a gradation of response according to the $H$-2 haplotype of the strain grafted. He has found that skin grafts among nonrecombinants carrying the $H-2^{b}$ haplotype reject rapidly, $d, k$, and $r$ haplotype strains are intermediate responders and $f$ and $p$ strains are slow or nonresponders.

Studies by Wikstrand and co-workers (1974) have demonstrated the same haplotypic influence on the vigor of the female's response to injected syngeneic male peritoneal exudate cells (PEC). They have found that, in addition to the $\mathrm{H}-2^{b}$ haplotype, the $H-2^{s}$ haplotype, as expressed in the A.SW strain, is associated with a strong response. These investigators postulate a polymorphic gene mapping within the $H-2$ complex regulating the response to the $\mathrm{H}-\mathrm{Y}$ antigen. Murine female $\mathrm{T}$ cells are also capable of generating cytotoxic killer $\mathrm{T}$ lymphocytes against the $\mathrm{Y}$ antigen of male cells (von Boehmer et al. 1978). $H-2^{b}$ animals are also strong reactors in this system and $H-2^{k}$ animals are weak reactors.

Liver-slice-to-kidney-bed grafts used in our laboratory (Schultz et al. 1976, 1977, 1978) permit the detection of a greater variety of immunological responses than those which can be identified in skin grafts. This grafting system also provides an in vivo environment lacking in methods currently used in many immunogenetic studies which employ some form of tissue culture. Because liver-to-kidney-bed grafts simulate many of the features of a clinical surgical grafting procedure, it is advantageous to see if the $\mathrm{H}-\mathrm{Y}$ rejection response elicited is similar to that reported for skin, bone marrow and PEC, and if the $H$ - 2 type exerts the same influence on the strength of the response. It will also be of interest to ascertain whether the portion of the genome adjacent to the $H-2$ complex has a greater or lesser role in anti-H-Y response in this grafting environment than in previously tested environments. Also of interest will be the effect, if any, of genetic background (meaning the portion of the genome aside from the $H-2$ complex), or interaction of $H-2$ haplotype with genetic background upon the degree of response.

\section{Materials and Methods}

Mice of the following strains were obtained from the Jackson Laboratory, Bar Harbor, Maine: C57BL/10Sn, C57BL/10J, C57BL/6J, C3H.SW, 129/J, LP/J $\left(H-2^{b}\right) ;$ C57BL/KsJ $\left(H-2^{k}\right) ;$ C57BR/cdJ, C58/J $\left(H-2^{d}\right) ; \mathrm{SJL} / \mathrm{J}, \mathrm{A} . \mathrm{SW}\left(H-2^{s}\right) ; \mathrm{DBA} / 1 \mathrm{~J}\left(H-2^{q}\right) ; \mathrm{C} 3 \mathrm{H} . J \mathrm{~K} / \mathrm{Sn}\left(H-2^{j}\right) ; \mathrm{A} . \mathrm{CA} / \mathrm{Sn}\left(H-2^{f}\right) ; \mathrm{C} 3 \mathrm{H} . \mathrm{NB} / \mathrm{Sn}$ $\left(H-2^{p}\right) ; \mathrm{B} 10 . \mathrm{Y} / \mathrm{Sn}\left(H-2^{p a}\right) ; \mathrm{B} 10 . \mathrm{RIII}(71 \mathrm{NS}) / \mathrm{Sn}\left(H-2^{r}\right) ; \mathrm{B} 10 . \mathrm{PL}(73 \mathrm{NS}) / \mathrm{Sn}\left(H-2^{u}\right) ; \mathrm{B} 10 . \mathrm{SM}(70 \mathrm{NS}) / \mathrm{Sn}\left(H-2^{v}\right)$. The National Cancer Institute provided the following strains: Balb/cnN $\left(H-2^{d}\right) ; \mathrm{SJL} / \mathrm{N}\left(H-2^{s}\right)$; B10.PD/CzN $\left(H-2^{b}\right)$; DBA/2N $\left(H-2^{d}\right)$. Mice of the strain B10.BR $\left(H-2^{k}\right)$ were donated by Dr. John Niederhuber of the University of Michigan. B10.M $\left(H-2^{f}\right), \mathrm{B} 10 . \mathrm{S}\left(H-2^{s}\right), \mathrm{C} 3 \mathrm{H}\left(H-2^{k}\right), \mathrm{B} 10 . \mathrm{D} 2\left(H-2^{d}\right)$ and C57BL/10Sn $\left(H-2^{b}\right)$ were bred in our own colony at the Ann Arbor Veterans Administration Medical Center. Dr. Robert Erickson, Human Genetics Department, University of Michigan, donated stock A.BY $\left(H-2^{b}\right)$ to our colony. All mice were grafted between the ages of 2 and 6 months. In all strains studied, four mice were killed at 35 days after grafting, and five were killed 70 days after grafting. If histological evaluation did not show good agreement at a particular time period or if the fate of the grafts, i. e., rejection or acceptance, was not obvious for a particular strain, then five grafts were studied at 105 days and/or 140 days after grafting. In some cases, further grafts were studied at 70 days after grafting for confirmatory purposes. 
Grafting procedure. The grafting method is based on the procedure used by Wheeler and co-workers (1966). Our modi operentia have been fully described previously (Schultz et al. 1976). In brief, a small piece of liver taken from an anesthesized donor is placed on the etherized recipient's left kidney which has been prepared by removing a shallow subcapsular slice. The recipient's abdominal incision is sutured and the mouse returned to the animal colony. Although one donor can provide liver for all grafts of a series, usually several donors are used to control for possible autogenous results. At predetermined time periods, the recipient mice are killed by cervical dislocation. Grafted kidneys are removed, fixed, trimmed, embedded, sectioned and stained. Numerous sections of each grafted kidney are screened to locate the central area of the graft. Three slides containing sections from the most central areas of the graft are then evaluated by the three authors.

Criteria for evaluation. Slides from replicate animals and serial time periods are evaluated on different days. Slides are examined without knowledge of the donor/recipient combinations, time period, or experiment to minimize subjective interpretations. A graft is first evaluated for rejection or survival by the presence of hepatocytes. The state of immunological reactivity of the host to the graft is judged by the quantity and nature (nodular or scattered) of lymphocytic infiltration, the quantity and physical state of fibrovascular tissue repopulating the graft (young and active or old and collagenized), the distribution of hepatocytes (well-organized as in a syngeneic graft, active and proliferating, or scattered and degenerating) and the appearance of the scar (newly formed or mature). Technical failures of grafts in this system are minimal and are easily distinguished from rejected grafts since hemosiderin laden macrophages mark the graft site.

The scoring system for evaluating graft-host interaction for minor loci (Schultz et al. 1978) was used in the male-female chronic rejection patterns. This system uses (P) to identify a proliferating graft with more than four layers of hepatocytes with or without cellular immunological activity, (S) to identify a syngeneic-like graft with 3-4 well organized layers of hepatocytes with little or no cellular immunological activity, $(\mathrm{C}-1)$ to identify a healthy graft with a few lymphocytes concentrated or in small nodules at the graft-bed interface, $(\mathrm{C}-2)$ to identify a graft containing less healthy, poorly organized hepatocytes with a considerable number of lymphocytes scattered throughout the graft, (C-3) to identify a graft containing degenerating scattered hepatocytes, copious lymphocytic infiltrate and fibrovascular tissue, (C-4) to identify a graft with lymphocytes present in large nodules and with only a few scattered hepatocytes in a young scar, (C-5) to identify a graft consisting of fibrovascular tissue with some collagen (young scar), a few lymphocytes present and no hepatocytes in evidence and $(C-6)$ to identify a graft with only a matured (contracted) scar from which most lymphocytes have receded. The appearance of a graft identified as C-6 is indistinguishable from the appearance of an acutely rejected graft such as seen across an $H-2$ barrier.

\section{Results}

Twenty-seven inbred strains of mice carrying 11 unrelated $\mathrm{H}-2$ haplotypes were chosen to evaluate the role of the $H-2$ complex and genetic background in host reaction to liver-to-kidney-bed grafts across the $\mathrm{H}-\mathrm{Y}$ barrier (Tables $1 \& 4$ ).

Females of strains possessing the $H-2^{b}$ haplotype totally reject their male counterpart's liver grafts leaving only scar tissue and hemosiderin laden macrophages to mark the graft site. The rejection culminated 28 to 42 days after grafting. Older ( 7 months) females showed no differences in response from younger females, 2-3 months old (Table 2). Male-to-male grafts showed good survival. Two hundred ten days after grafting, the hepatocytes were growing in an organized layer, $3-4$ cells thick. No inflammatory cells were present in these grafts. At the same time after grafting (210 days), some of the female-to-male grafts were syngeneic-like and others were proliferating. Retired breeder females ( 7 months old) did not reject grafts at 35 days as did "virgin" females, but rather showed a very minimal (C-1) immunologic response. The C57BL/6J strain mice, although closely related to the C57BL/10 strain, and serologically identical to all $H-2^{b}$ haplotypes strains did not react in the 


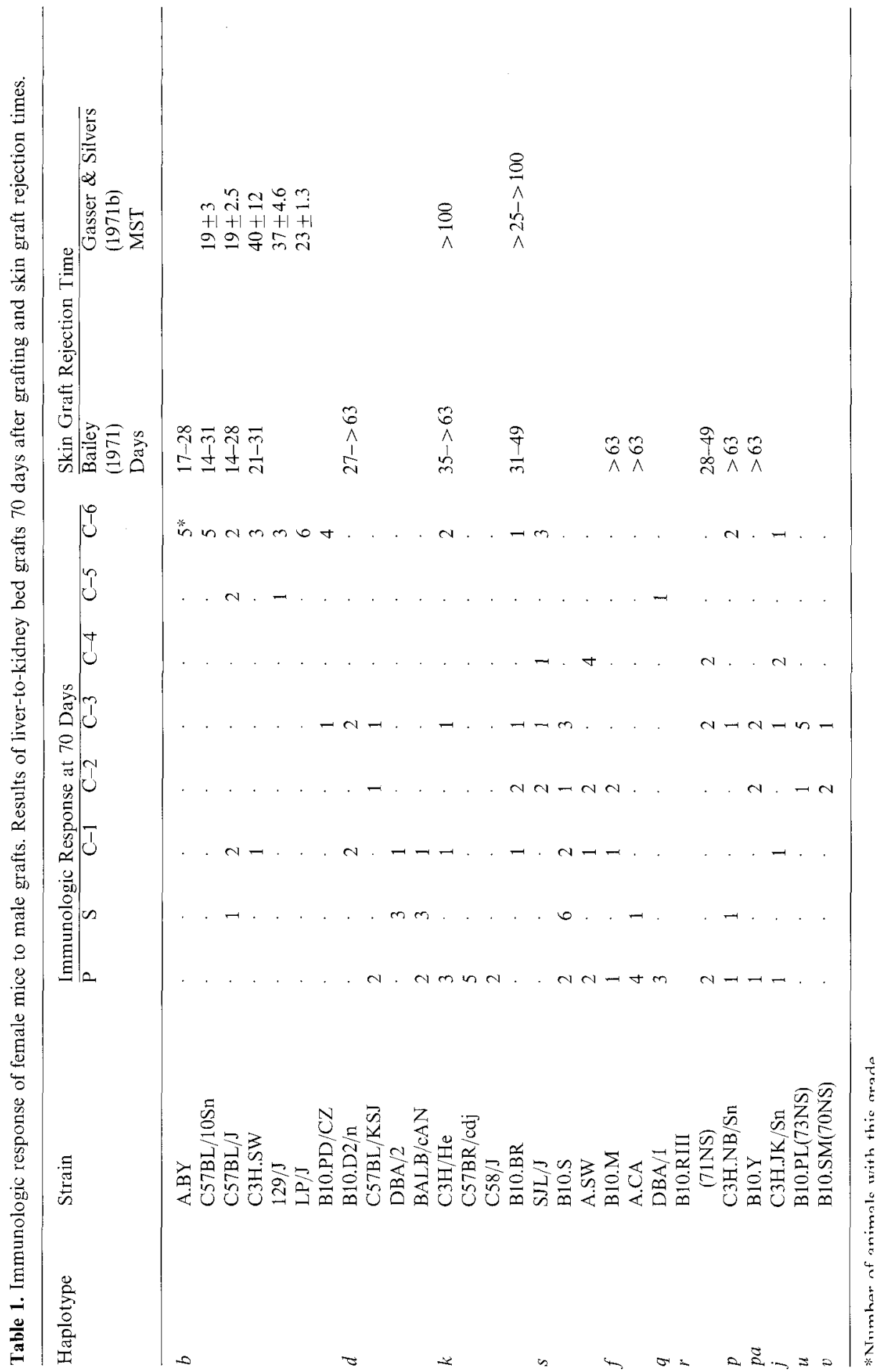


Table 2. Comparison of immunological responses of C57BL/10Sn mice. Number in parentheses indicates total number of mice with that score

\begin{tabular}{|c|c|c|c|c|}
\hline & \multicolumn{4}{|c|}{ Days after grafting } \\
\hline & $\overline{35}$ & 42 & 70 & 210 \\
\hline Male-to-male & & & & $\begin{array}{l}\mathrm{P}(1) \\
\mathrm{S}(3)\end{array}$ \\
\hline Female-to-male & & & $\begin{array}{l}S(2) \\
C-6(1)\end{array}$ & $\begin{array}{l}P(3) \\
S(3)\end{array}$ \\
\hline $\begin{array}{l}\text { Male-to-female } \\
\text { Nonbreeders }\end{array}$ & & & & \\
\hline 2-3 months old & $\begin{array}{l}\mathrm{C}-3(1) \\
\mathrm{C}-5,6(7)\end{array}$ & $\begin{array}{l}C-4(1) \\
C-6(3)\end{array}$ & $C-6(2)$ & \\
\hline 7 months old & $\begin{array}{l}C-4(1) \\
C-5,6(3)\end{array}$ & & & \\
\hline $\begin{array}{l}\text { Retired breeders } \\
7 \text { months old }\end{array}$ & $\begin{array}{l}\mathrm{C}-1(3) \\
\mathrm{C}-3(1)\end{array}$ & & & \\
\hline
\end{tabular}

same manner as other mice carrying the $H-2^{b}$ haplotype. Four of seven C57BL/6J females rejected their male liver grafts by 70 days after grafting (C-5 and C-6), but one reacted in a syngeneic-like manner $(\mathrm{S})$ and two others were only slightly more reactive $(\mathrm{C}-1)$. This variation of reaction was also apparent at an earlier time period. Approximately one-half of the grafts are rejected and one-half survive 35 days after grafting.

Extensive graft rejection was associated with another haplotype, $H-2^{s}$, but then with one strain only, the SJL strain. All male liver grafts were found to have elicited a strong immunologic response from SJL females at 70 days after grafting $(\mathrm{C}-2, \mathrm{C}-3$, $\mathrm{C}-4$, etc.) and the majority of grafts were rejected by 35 days. B10.S and A.SW hosts, also serologically typed as $H-2^{s}$, reacted with either a syngeneic-like or proliferative response (Fig. 1), or showed mild immunologic reaction.

No other $H$-2 haplotype could be associated with any characteristic pattern of immunologic reaction regardless of the genetic background of the mouse strain expressing it. The average level of reaction at 70 days after grafting was most frequently $\mathrm{C}-2$, that is, a graft with less healthy, poorly organized hepatocytes and with inflammatory cells extending throughout the graft (Fig. 2). In many strains, some grafts expressed chronic immunologic activity.

Hosts carrying the $H-2^{k}$ haplotype varied in their responses. The C58/J female's response resulted in proliferation of the male liver graft. However, the B10.BR female's response varied from C- 1 to C-6 at 70 days after grafting but did not generally result in proliferation. Balb/c and DBA/2 animals $\left(H-2^{d}\right)$ accepted their male liver grafts $(\mathrm{S})$ or showed a mild immunologic response 70 days and 105 days after grafting. No lymphocytes were visible in the graft area of Balb/c female mice, even at 105 days after grafting. The liver mass at 105 days had begun to erode and no longer consisted of a continuous band of healthy appearing hepatocytes, but no inflammatory response was evident. 


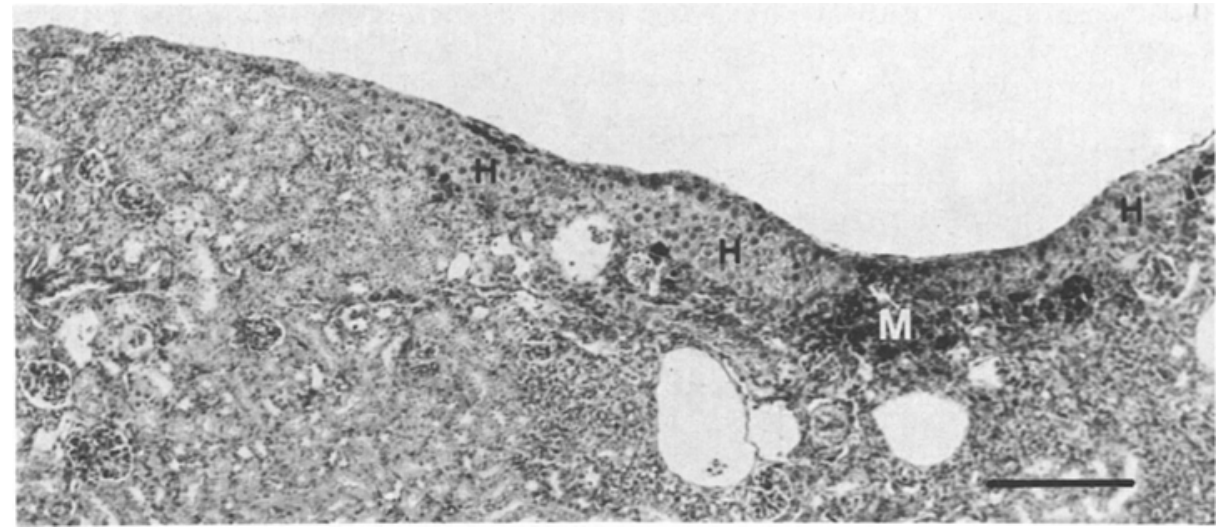

Fig. 1. $\mathrm{B} 10 . \mathrm{S}\left(H-2^{s}\right)$ liver to $\mathrm{B} 10 . \mathrm{S}\left(H-2^{s}\right)$ kidney graft, 70 days after grafting with grade $\mathrm{S}$ reaction (syngeneic-like). Hepatocytes - H. Hemosiderin-laden macrophages - M. The scale mark equals $0.2 \mathrm{~mm}$.

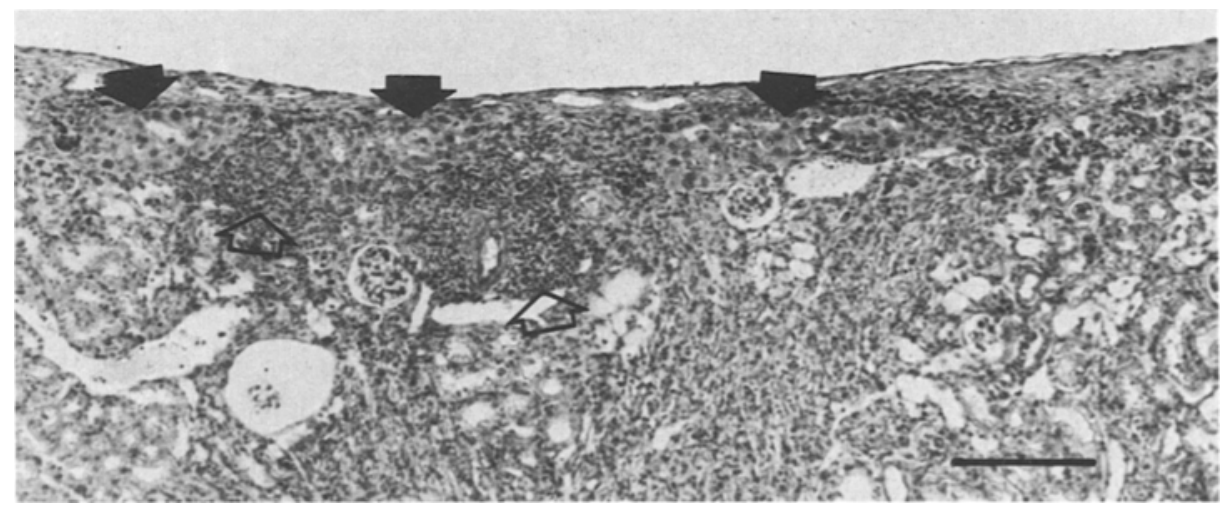

Fig. 2. $\mathrm{B} 10 . \mathrm{Y}\left(H-2^{p a}\right)$ liver to $\mathrm{B} 10 . \mathrm{Y}\left(H-2^{p a}\right)$ kidney graft, 70 days after grafting with grade $\mathrm{C}-2$ reaction. Solid arrows point to nests of residual hepatocytes. Open arrows ind icate nodules of imflammatory cells at the interface and extending into the graft. The scale mark equals $0.2 \mathrm{~mm}$.

B10.M $\left(H-2^{f}\right)$ mice, which were reported to be nonresponders in all previously studied male-to-female grafting systems, were grafted female-to-female as well as male-to-female. Some grafts in all of these $H-2^{f}$ combinations proliferated and some grafts showed mild immunologic response (C-1) 70 days after grafting. However, at an earlier time (21 days after grafting) the female-to-male grafts showed mild to moderate immunologic activity $(\mathrm{C}-1$ and $\mathrm{C}-2)$, whereas male-to-female grafts were syngeneic-like in appearance. Male-to-female grafts studied 140 days after grafting were all proliferating. Large aggregates of polymorphonuclear leukocytes were seen around the graft area even at 140 days after grafting. There were no or few lymphocytes present. This response, consisting of aggregates of polymorphonuclear leukocytes but only rare lymphocytes, was not seen in other strains. A.CA mice, 
another $\mathrm{H}-2^{\mathrm{f}}$ strain, showed proliferating grafts at both 70 and 140 days after grafting.

The immunological response of the DBA/1 strain females $\left(H-2^{q}\right)$ to the male grafts also resulted in proliferation of the hepatocytes. The DBA/1 graft areas contained some lymphocytes.

The $H-2^{j}$ haplotype is classified as a member of the "partially related" group, i. e., it contains an $H-2 K$ region serologically unrelated to any other known $H-2 K$, but an $H-2 D$ region serologically identical to known $H-2 D$ regions (Klein 1975 and Klein et al. 1978). The C3H.JK/Sn strain which is $H-2^{j}$ had variable but strong immunological response at 70 days after grafting. However, by 140 days the grafts had recovered and were mostly proliferative. B10.SM(70NS)/Sn $\left(H-2^{v}\right)$ females, also categorized as "partially related" (see Discussion) reacted moderately. Females of the third "partially related" strain, B10.PL(73NS)/Sn $\left(H-2^{u}\right)$ respond more strongly, most of the graft reactions being in the $\mathrm{C}-3$ range. B.10.RIII(71NS)/Sn $\left(H-2^{r}\right)$ females responded with either a strong $(\mathrm{C}-4)$ reaction or the liver grafts proliferated at 70 days after grafting.

The strain C3H.NB $\left(H-2^{p}\right)$ showed a wide range of immunological reactivity in male-to-female liver grafts, varying from proliferating grafts to graft rejection. $H-2^{p a}$ is a minor variant of $H-2^{p}$ expressed in the B10.Y strain. B10.Y females exhibited a moderate level of reaction $(\mathrm{P}, \mathrm{C}-2, \mathrm{C}-3)$ to male liver grafts.

\section{Discussion}

Initially, strains of mice for which male-to-female skin graft data are available were selected for liver-to-kidney-bed grafting so that the two grafting systems could be compared. The acute, unequivocal graft rejection by $H-2^{b}$ haplotype female makes possible a direct comparison of our microscopic analysis at predetermined time periods with skin graft data for strains carrying this haplotype. However, as skin graft data is based on day of sloughing, it is more difficult to compare skin graft data with liver graft results in strains which carry haplotypes which react less vigorously to the $\mathrm{H}-\mathrm{Y}$ antigen. For instance, B10.BR females $\left(H-2^{k}\right)$, respond to male liver grafts with reactions ranging from $P$ to $C-3$ at 35 days after grafting and $C-1$ to $C-6$ at 70 days after grafting, whereas skin graft rejection times vary from 30 to 50 days (Bailey 1971) or 25 to 100 days (Gasser and Silvers 1971b) (Table 1).

Grafts from all strains of mice were examined at two time points, 35 and 70 days after grafting. Based on results at these times, some strains were further studied at 105 and/or 140 days after grafting. Some strains were consistent in their reactivity for one time period and some were not. However, consistency or lack thereof was independent of the $\mathrm{H}-2$ allele carried by the strain. The nature of the cellular infiltrate was strain specific, e. g., male-to-female grafts of the B10.PL(73NS) strain were largely accompanied by polymorphonuclear cells as well as lymphocytes.

Eighty percent of nonbreeder $\mathrm{C} 57 \mathrm{BL} / 10 \mathrm{Sn}$ females $\left(H-2^{b}\right)$ rejected their male liver grafts at 35 days after grafting. The remaining $20 \%$ showed immunologic activity in the $\mathrm{C}-3$ or $\mathrm{C}-4$ range. However, female $\mathrm{C} 57 \mathrm{BL} / 10 \mathrm{Sn}$ retired breeders showed little reactivity to the male grafts (three grafts $\mathrm{C}-1$, one graft $\mathrm{C}-3$ ). These females presumably demonstrate tolerance acquired from exposure to the $\mathrm{H}-\mathrm{Y}$ antigens of their male offspring during gestation (Table 2). 
Females of strains bearing the $H-2$ haplotypes $d, k$ and $r$ that typically show some male skin graft rejection, do not reject male liver grafts even as late as 70 days after grafting. Whether this is a result of an immunological difference due to tissuespecific antigens of liver and skin or to cell surface presentation of H-Y antigens cannot be determined at this time. The liver-to-kidney-bed graft initially undergoes a crisis, due to surgical trauma, characterized by necrosis of a large portion of the grafted tissue (Beals et al., in preparation). In acutely rejecting grafts between $\mathrm{H}-2$ disparate mice, the entire graft becomes necrotic, possibly because the remaining hepatocytes are overwhelmed by the influx of $T$ cells. These $T$ cells (as current data indicate) may leave the circulation to be sequestered while they undergo extensive proliferation for 4-5 days in response to the foreign antigen. These cells would then return in large numbers to the circulation to be mobilized against the foreign tissue (Sprent 1978). Grafts across minor immunologic barriers (e.g., between mice disparate for certain subregions of the $\mathrm{H}-2$ complex only or for non- $\mathrm{H}-2$ histocompatibility regions) recover from the grafting crisis, but rejection may then occur at any time when immunological destruction proceeds faster than new hepatocytes can be formed, or when the immunological attack prevents hepatocyte replacement, gradually eroding the cell mass. Apparently only a few liver cells need to survive for graft recuperation. Therefore, a more concentrated immunological response may be essential for the total destruction of grafted liver than for rejection of grafted skin which may occur with the loss of far fewer cells. This difference in rejection times between the liver and skin grafts may reflect a differential response to cellular and humoral components, possibly due to greater availability of donor liver cells to the host's circulation than of grafted skin cells which are protected by the mucopolysaccharide barrier (Sena et al. 1976).

Since many of the congenic mouse strains that reject over the $\mathrm{H}-\mathrm{Y}$ barrier derive from the founder stock of Ms. A.E.C. Lathrop of Grandby, Massachusetts, we decided to see if a high responder trait could be traced to its "roots" and if related strains, not bearing the $H-2^{b}$ haplotype, might have retained this trait. Table 3 shows that no high responder gene has been inherited independent of $H-2$ type in the many strains of mice derived from the fancy coated mice produced during the fad of the early $1900 \mathrm{~s}$. Only the females of strains with $H-2^{b}$ haplotypes consistently reject their male partner's liver graft. No association with coat color or background is evident in mice derived from this source.

The question of background genome was also investigated. Does placing a haplotype on a different background provide a new milieu conducive to an altered $\mathrm{H}-\mathrm{Y}$ recognition response, or does a particular $\mathrm{H}-2$ haplotype behave similarly on all backgrounds? The results presented in Table 1 and Figure 3 show that, in most cases, the responses of the various haplotypes are independent of the non- $\mathrm{H}-2$ portion of the genome. Two exceptions are the C57BL/6 strain and the SJL strain which behave differently from other $H-2^{b}$ and $H-2^{s}$ mice, respectively. These differences may be due to genes closely linked to the $H-2$ or to the male's H-Y antigen or other background differences in these strains.

It has also been suggested that $\mathrm{H}-\mathrm{Y}$ antigen expression may be dependent upon the $H-2$ phenotype of the donor (Wachtel et al. 1973 and Králova and Démant 1976). The results reported here do not make it possible to attribute responsibility for differences of strengths of liver tissue rejection to either differences in strengths of 
Table 3. Interrelationships of common inbred strains and domesticated, fancy-coated pet mice. Loosely based on Klein (1975) and Potter and Lieberman (1967)

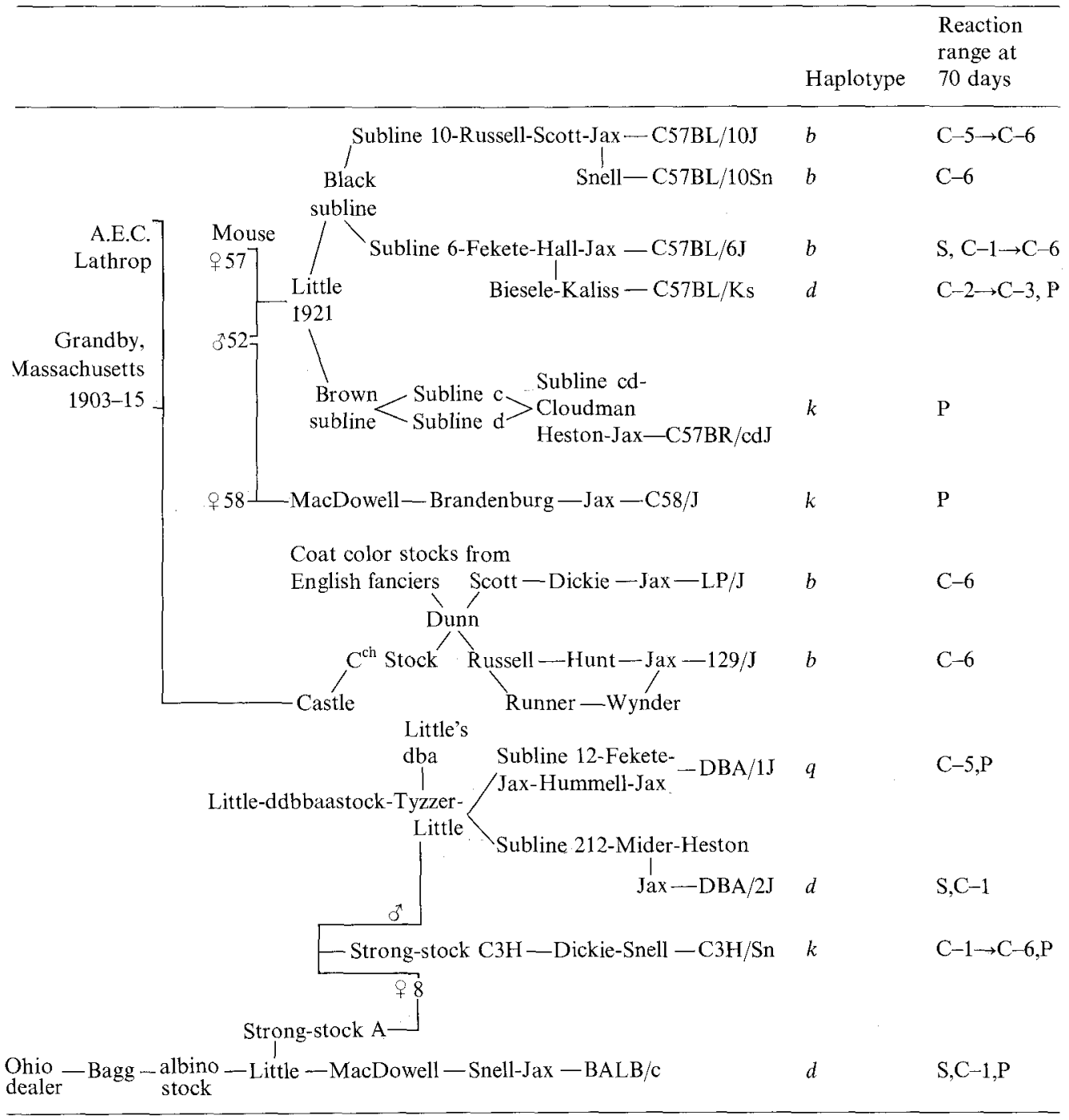

H-Y expression or to $H-2$ associated differences in immune response of the female to the $\mathrm{H}-\mathrm{Y}$ antigen.

$H-2^{j}, H-2^{u}$ and $H-2^{v}$ are $H-2$ haplotypes bearing $H-2 K$ regions that are unrelated to those of any other known haplotype or to each other. However, they share serologically determined private antigens of the $H$-2D region and some, but not all, public antigens with known haplotypes. Although these haplotypes were undoubtedly derived from more common types by mutation and recombination, their exact origins are unknown (Klein 1975). $H-2^{j}$ has a $D$ region similar to that of 
$H-2^{b}$. C3H.JK/Sn, a strain carrying $H-2^{j}$, has a much more vigorous early anti-H-Y response than any haplotype other than $H-2^{b}$, implicating the involvement of the $H-2 D^{b}$ portion of the allele. However, these grafts do tend to recover by 140 days after grafting. B10.PL(73NS)/Sn has the $H-2^{u}$ haplotype, which is characterized by a $D$ region seemingly identical to that of $H-2^{d}$. The response of $H-2^{u}$ female mice to the $\mathrm{H}-\mathrm{Y}$ antigen was not unlike that of $H-2^{d}$ female mice (C-2). $H-2^{v}$ shares its D-region antigens with $H-2^{q}$. B10.SM(70NS)/Sn $\left(H-2^{v}\right)$ has a $\mathrm{C}-2, \mathrm{C}-3$ anti-H-Y response totally different from the DBA/1 $\left(H-2^{q}\right)$ strain's proliferative anti-H-Y reaction. From these data, it does not appear that the $D$ end of the $H-2$ complex alone influences male-to-female graft rejection. Further confusion as to the influence of portions of the $H-2$ complex is forthcoming (Schultz et al. in preparation).

The discordant reactions among our $H-2^{s}$ strains would indicate that a mechanism not controlled by the MHC is active in male-to-female graft rejection in the SJL mouse strain. Mice of strain SJL have an age-related immune system defect characterized by a loss of immune regulation resulting in a hyperresponsiveness to alloantigens (Owens and Bonavida 1976). The $I r$ region of the $H-2$ complex is

Table 4. Immunologic response of female mice to male grafts at various times after grafting

\begin{tabular}{|c|c|c|c|c|c|c|c|c|c|c|c|c|c|c|}
\hline Days after grafting & 35 & & & & & & & 70 & & & & & & \\
\hline Score & $\mathrm{P}$ & $\mathrm{S}$ & $\mathrm{C}-1$ & $C-2$ & $C-3$ & $\mathrm{C}-4$ & $\mathrm{C}-5,6$ & $\mathrm{P}$ & $\mathrm{S}$ & $\mathrm{C}-1$ & $\mathrm{C}-2$ & $\mathrm{C}-3$ & $C-4$ & $\mathrm{C}-5,6$ \\
\hline \multicolumn{15}{|l|}{ Allele/Strain } \\
\hline$b$ A.BY & & - & . & . & ND & $\cdot$ & & & & & - & & . & $5 *$ \\
\hline C57BL/10Sn & . & . & . & . & 1 & . & 7 & . & . & & . & . & . & 5 \\
\hline C57BL/6J & · & . & . & . & 2 & & 2 & . & 1 & 2 & . & , & . & 4 \\
\hline C3H.SW & $\cdot$ & . & - & . & . & . & 4 & . & . & 1 & - & . & . & 3 \\
\hline $129 / \mathrm{J}$ & 1 & . & . & . & . & 2 & $\cdot$ & & & . & . & . & · & 4 \\
\hline $\mathrm{LP} / \mathrm{J}$ & . & . & . & . & ND & . & . & . & . & & . & . & . & 6 \\
\hline B10.PD/CZ & . & $\cdot$ & . & $\cdot$ & 1 & . & 2 & . & & $\cdot$ & - & 1 & . & 4 \\
\hline \multirow{4}{*}{$\begin{array}{ll}d & \text { B10.D2/n } \\
\text { C57BL/KSJ } \\
\text { DBA } / 2 \\
\text { BALB } / \mathrm{C}\end{array}$} & & . & . & 3 & . & . & . & . & . & 2 & . & 2 & . & . \\
\hline & . & 1 & . & . & 1 & . & & 2 & . & & 1 & 1 & . & . \\
\hline & 1 & 2 & . & . & $\cdot$ & . & & $\cdot$ & 3 & 1 & & . & & \\
\hline & & · & . & $\therefore$ & ND & . & & 2 & 3 & 1 & . & & . & \\
\hline \multirow{4}{*}{$\begin{array}{ll}k & \mathrm{C} 3 \mathrm{H} / \mathrm{He} \\
& \mathrm{C} 57 \mathrm{BR} / \mathrm{cdJ} \\
& \mathrm{C} 58 / \mathrm{J} \\
& \mathrm{B} 10 . \mathrm{BR}\end{array}$} & & & & - & $\mathrm{ND}$ & & & 3 & . & 1 & . & 1. & - & 2 \\
\hline & 3 & . & . & . & 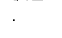 & . & & 5 & & . & . & . & . & . \\
\hline & . & . & . & . & $\mathrm{ND}$ & . & . & 2 & . & . & . & . & . & . \\
\hline & 1 & . & 2 & $\cdot$ & 1 & . & . & . & & 1 & 2 & 1 & & 1 \\
\hline \multirow{3}{*}{$\begin{array}{l}s \quad \mathrm{SJL} / \mathrm{J} \\
\mathrm{B} 10 . \mathrm{S} \\
\mathrm{A} . \mathrm{SW}\end{array}$} & $\cdot$ & . & 1 & I & . & 2 & 4 & . & . & & 2 & 1 & 1 & 3 \\
\hline & $\cdot$ & . & 4 & $\cdot$ & . & 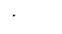 & . & 2 & 6 & 2 & 1 & 3 & $\cdot$ & $\cdot$ \\
\hline & 3 & . & $\cdot$ & , & 1 & 1 & . & 2 & $\cdot$ & 1 & 2 & . & 4 & . \\
\hline$f$ B $10 . \mathrm{M}$ & $\cdot$ & . & . & . & ND & . & . & 1 & . & 1 & 2 & . & . & . \\
\hline A.CA & . & . & . & . & ND & . & . & 4 & 1 & . & . & . & . & . \\
\hline$q \mathrm{DBA} / 1$ & 1 & 1 & 1 & . & $\cdot$ & 1 & & 3 & & . & . & . & . & 1 \\
\hline \multicolumn{15}{|l|}{$r$ B10.RIII } \\
\hline (7INS) & & & & 2 & 2 & & & 2 & . & & & 2 & 2 & . \\
\hline$p \quad \mathrm{C} 3 \mathrm{H} \cdot \mathrm{NB} / \mathrm{Sn}$ & 1 & 1 & 1 & . & & & & 1 & 1 & . & . & 1 & . & 2 \\
\hline pa BIO.Y & 1 & & & 1 & 2 & & . & 1 & . & . & 2 & 2 & . & $\cdot$ \\
\hline j C3H.JK/Sn & & . & . & . & 2 & 1 & & 1 & . & 1 & . & 1 & 2 & 1 \\
\hline \multicolumn{15}{|l|}{$u \quad \mathrm{~B} 10 . \mathrm{PL}$} \\
\hline$(73 N S)$ & & & . & & ND & & & . & . & . & 1 & 5 & . & . \\
\hline \multicolumn{15}{|l|}{$v \quad \mathrm{~B} 10 . \mathrm{SM}$} \\
\hline (70NS) & 1 & & 1 & . & . & & . & . & . & . & 2 & 1 & . & \\
\hline
\end{tabular}

* Number refers to number of animals with this graft grade. 
thought to code for the immune response, with IA-IJ interaction possibly controlling T-cell subset coordination, but the Ir region does not seem to be the controlling factor for SJL male liver graft rejection. The hyperresponsiveness to an alloantigen (in this case $\mathrm{H}-\mathrm{Y}$ ) would seem to be a by product of altered immune cell cooperation, itself possibly the result of abnormal thymic activity (Ben-Yaakov and Haran Ghera 1975) which may be controlled by a gene or genes outside of the $H-2$ complex.

The response of female mice to syngeneic male liver grafts shows an $H-2$ haplotype influence as reported for other grafting systems. Whereas female mice of the $H-2^{b}$ haplotype reject male liver grafts acutely in the same way that they reject grafts of other tissues, females bearing other haplotypes, notably $\mathrm{H}-2^{d}, \mathrm{H}-2^{k}$ and $H-2^{r}$ do not respond to liver grafts in the same way as they respond to skin grafts. SIL female mice reacted with an atypically strong immune response which differs from the response of other $\mathrm{H}-2^{s}$ bearing strains but which is compatible with the reported hyperresponsiveness of SJL mice to alloantigens.

Skin graft and PEC graft studies in recombinant mouse strains have de-

\begin{tabular}{|c|c|c|c|c|c|c|c|c|c|c|c|c|c|}
\hline \multicolumn{7}{|c|}{105} & \multicolumn{7}{|c|}{140} \\
\hline P & S & $C-1$ & $\mathrm{C}-2$ & $C-3$ & $C-4$ & $C-5,6$ & $P$ & $\mathrm{~S}$ & $C-1$ & $\mathrm{C}-2$ & $C-3$ & C-4 & $C-5,6$ \\
\hline & & & & $\mathrm{ND}$ & & & & & & & ND & & \\
\hline & . & & & ND & & . & . & . & . & & ND & . & \\
\hline & & & & ND & . & . & . & & & & ND & & \\
\hline . & & . & & ND & & . & . & & & & ND & & \\
\hline & & & & ND & . & . & . & & . & & ND & & \\
\hline . & & & & ND & & . & . & . & . & & ND & & . \\
\hline & & & & ND & & & & & & & ND & . & \\
\hline & & & & ND & & & & & . & . & ND & & . \\
\hline & & & & ND & & & & . & & . & ND & . & \\
\hline & . & & & ND & & & & & . & . & ND & & \\
\hline 1 & 1 & . & 2 & 2 & . & . & & & & & ND & & . \\
\hline & 2 & 1 & 1 & & . & 1 & 4 & & & & 2 & & 1 \\
\hline & $\cdot$ & . & & ND & . & & & & & . & ND & & \\
\hline 3 & . & 1 & & & . & . & & & . & . & ND & & \\
\hline$\cdot$ & . & & & ND & & & & & . & . & ND & & . \\
\hline & & & & ND & . & . & & & . & . & ND & & . \\
\hline & & . & & ND & . & . & & . & . & . & ND & & \\
\hline 3 & & & & 1 & . & 1 & 3 & & 3 & . & & . & 1 \\
\hline & & . & & ND & & & 6 & & . & . & & &. \\
\hline & & . & & ND & & & 4 & & 1 & . & & & . \\
\hline & $\cdot$ & $\cdot$ & & ND & & & & & & & ND & & \\
\hline . & . & & . & ND & . & & & 1 & 1 & 4 & & & \\
\hline . & . & . & . & ND & & . & 1 & 2 & . & 2 & & & \\
\hline . & & & . & ND & . & & & & & & $\mathrm{ND}$ & & \\
\hline & & & . & ND & . & $\cdot$ & 6 & & . & . & & . & 1 \\
\hline & & & & ND & & & & & . & . & ND & & . \\
\hline & & & & ND & & & & & & & ND & & \\
\hline
\end{tabular}




\section{BACKGROUND EFFECT}

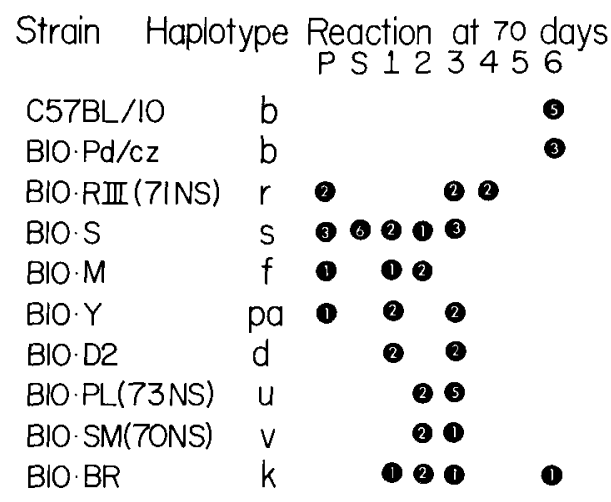

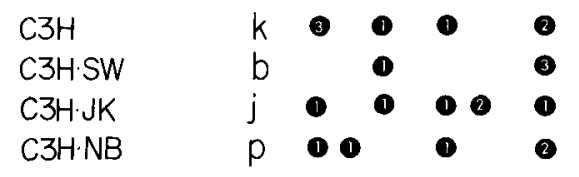
$A \cdot B Y$
ASW
ACA

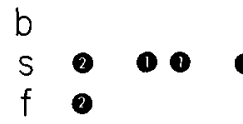
Fig. 3. Response of female mice to male liver grafts influenced by haplotype independent of the non- $H-2$ portion of the genome.

monstrated involvement of the $I$ region of the $H-2$ complex in the anti-H-Y response. Results of liver-to-kidney-bed grafts in $H-2^{b}$ haplotype recombinant and mutant strains indicate that the graft response mechanism may be much more complex than studies of other grafting systems have indicated. A report of these results is in preparation.

Acknowledgements. Supported by the Medical Research Service of the Veterans Administration and National Cancer Institute Grant CA18638.

\section{References}

Bailey, D. W.: Allelic forms of a gene controlling the female immune response to the male antigen in mice. Transplantation 11:426-428, 1971

Bailey, D. W. and Hoste, J.: A gene governing the female immune response to the male antigen in mice. Transplantation 11:404-407, 1971

Ben-Yaakov, M. and Haran-Ghera, N.: T \& B lymphocytes in thymus of SJL/J mice. Nature $255: 64-66$, 1975

Eichwald, E. J. and Silmser, C. R.: Communication. Transplant. Bull. 2:148-149, 1955

Gasser, D. L. and Silvers, W. K.: Genetic control of the immune response in mice. III. An association between $H-2$ type and reaction to H-Y. J. Immunol. 106:875-876, 1971a

Gasser, D. L. and Silvers, W. K.: The genetic basis of male skin rejection in mice. Transplantation 12:412$414,1971 b$

Gasser, D. L. and Silvers, W. K.: Genetics and immunology of sex-linked antigens. Adv. Immunol. 15:215-247, 1972 
Klein, E. and Linder, O.: Factorial analysis of the reactivity of C57BL females against isologous male skin grafts. Transplant. Bull. 27:457-459, 1961

Klein, J.: Biology of the Mouse Histocompatibility-2 Complex. Springer-Verlag, Berlin-Heidelberg-New York, 1975

Klein, J., Flaherty, L., VandeBerg, J. L., and Shreffler, D. C.: H-2 haplotypes, genes, regions and antigens: First listing. Immunogenetics 6:489-512, 1978

Králova, J. and Démant, P.: Expression of the H-Y antigen on thymus cells and skin: Differential genetic control linked to $\mathrm{K}$ end of $\mathrm{H}$-2. Immunogenetics 3:583-594, 1976

Owens, M. H. and Bonavida, B.: Immune functions characteristic of SJL/J mice and their association with age and spontaneous reticulum cell sarcoma. Cancer Res. 36:1077-1083, 1976

Potter, M. and Lieberman, R.: Genetics of immunoglobulins in the mouse. Adv. Immunol. 7:91-145, 1967

Schultz, J. S., Beals, T. F., and Petraitis, F. P.: Tissue graft rejection in mice. I. Contributions of $H-2$ and non-H-2 genetic barriers. Immunogenetics 3:85-96, 1976

Schultz, J. S., Beals, T. F., and DeMott-Friberg, R.: Tissue graft rejection in mice. II. Graft survival across H-2 regional barriers. Immunogenetics 4:315-325, 1977

Schultz, J. S., Beals, T. F., and DeMott-Friberg, R.: Tissue graft rejection in mice. V. Survival, rejection or proliferation across minor barriers. Immunogenetics 6:585-595, 1978

Sena, J., Wachtel, S. S., and Murphy, G.: A comparison of the survival of H-Y incompatible ear, tail and body skin grafts. Transplantation $21: 412-416,1976$

Sprent, J.: Role of the $H$-2 complex in induction of T-helper cells in vivo. I. Antigen-specific selection of donor T-cells to sheep erythrocytes in irradiated mice dependent upon sharing of $H-2$ determinants between donor and host. J. Exp. Med. 148:478-489, 1978

Stimpling, J. H, and Reichert, A. E.: Male-specific graft rejection and the $H-2$ locus. Trandsplantation $12: 527-531,1971$

von Boehmer, H., Haas, W., and Jerne, N. K.: Major histocompatibility complex-linked immuneresponsiveness is acquired by thymocytes of low responder mice differentiating in thymus of highresponder mice. Proc. Natl. Acad. Sci. USA.:2439-2441, 1978

Wachtel, S. S., Gasser, D. L., and Silvers, W. K.: Male-specific antigen: Modification of potency by the $H-2$ locus in mice. Science $181: 862-863,1973$

Wheeler, H. B., Carson, J. M., and Dammin, G. L.: Transplantation of tissue slices in mice. Ann. N. Y, Acad. Sci. 129:118-125, 1966

Wikstrand, C. J., Haughton, G., and Bailey, D. W.: The male antigen. II. Regulation of the primary and secondary responses to $\mathrm{H}-\mathrm{Y}$ by $\mathrm{H}-2$ associated genes. Cell Immunol 10:238-247, 1974

Received April 20,1979, revised version received July 23,1979 